Archaeological Prospection

Archaeol. Prospect. 22, 221-232 (2015)

Published online 28 April 2015 in Wiley Online Library

(wileyonlinelibrary.com) DOI: 10.1002/arp.1509

\title{
Characterization of a Pre-Trajan Wall by Integrated Geophysical Methods
}

\section{LUCIANA ORLANDO, ETTORE CARDARELLI, MICHELE CERCATO* AND GIORGIO DE DONNO}

\author{
Dipartimento di Ingegneria Civile Edile e Ambientale (DICEA), ‘Sapienza’ University of Rome, Rome, Italy
}

\begin{abstract}
The purpose of this study was to characterize a pre-Trajan mosaic-decorated wall structure located beneath the Cryptoporticus of the 'Baths of Trajan' complex in Rome. The surveyed wall is $15 \mathrm{~m}$ long, $0.9 \mathrm{~m}$ wide and 3 to $5 \mathrm{~m}$ high. Ground penetrating radar (GPR) and P-wave seismic refraction tomography profiles were used to reconstruct the wall's inner structure, generate a map of the fractures and to evaluate the seismic velocities of the building materials. The wall was surveyed with horizontally and vertically dense GPR profiles and two seismic lines. The seismic lines and GPR profiles were capable of detecting a discontinuity between brick and travertine materials that compose the wall. The combined interpretation of the two non-invasive techniques allowed us to locate weak zones and fractures. This rapid, non-destructive and multi-parametric approach has proved to be effective for characterizing the current status of the wall and the results will be used by archaeologists to evaluate the wall's integrity and to preserve the structure in the future archaeological excavations. Copyright (c) 2015 John Wiley \& Sons, Ltd.
\end{abstract}

Key words: Archaeological prospection; applied geophysics; non-destructive testing; ground penetrating radar; seismic tomography; geophysical inversion

\section{Introduction}

Over the past few decades, non-invasive geophysical techniques have been increasingly applied for the examination and characterization of ancient structures to support forthcoming archaeological investigations (Oswin, 2009; Piro, 2009). The integration of experimental data from different geophysical methods is generally the suggested approach to avoid interpretation ambiguities and pitfalls in the characterization of near-surface structures. Despite the large number of applications, a unified approach for data acquisition, processing, interpretation and monitoring is still lacking due to the variation in site characteristics, and therefore there is no standardized approach.

The ground penetrating radar (GPR) method uses the reflection of electromagnetic waves to image the subsurface, and well-established literature describes

* Correspondence to: M. Cercato, Dipartimento di Ingegneria Civile, Edile e Ambientale DICEA, Facoltà d'Ingegneria Civile e Industriale, 'Sapienza' Università di Roma, via Eudossiana 18, 00186 Rome, Italy. E-mail: michele.cercato@uniroma1.it its application to archaeological targets (Conyers, 2013; Goodman and Piro, 2013). This method can rapidly provide important information about the location and the geometry of buried bodies, without any damage to the structure under investigation. In particular, GPR has been successfully applied for archaeological purposes to detect and characterize ancient structures (Orlando and Slob, 2009; Cataldo et al., 2012), to locate cavities in ancient remains and hidden objects in the shallow subsurface (Neubauer et al., 2002; Piro et al., 2003), to highlight anomalous zones within ancient buildings and to assess the current state of structures with regard to their internal integrity [see, for instance, Goodman and Piro (2013) for a collection of successful case histories].

As GPR uses high frequency electromagnetic waves in the VHF/UHF range ( $30 \mathrm{MHz}$ to $3 \mathrm{GHz})$, the radar reflection profiles are generally characterized by higher resolution than other geophysical methods, although the depth of penetration is inversely proportional to the radiated frequency and severely affected by the electrical conductivity of the ground (Daniels, 2009). 
In contrast, seismic methods are used as a nondestructive test (NDT) for material characterization because the seismic velocities are directly linked to the elastic material stiffness at low strain (Mavko et al., 2009). Thus, low-velocity zones are straightforward indicators of material weakness. To this end, several studies have used seismic tomography to image the internal structures of buildings, structures and ancient monuments (Cardarelli and de Nardis, 1998; Cardarelli et al., 2002; Polymenakos et al., 2005). In the NDT literature, only a few studies have involved the application of multiple non-destructive testing methods, which we employ here (GPR and seismic tomography), for monitoring cultural heritage sites (Cardarelli et al., 2002; Orlando and Renzi, 2013; Pérez-Gracia et al., 2013).

The case study presented in this paper focuses on an integrated application of GPR and seismic tomography to characterize an ancient wall of pre-Trajan age, located in the historical centre of Rome (Figure 1). The wall under examination is of great artistic value because it is decorated with a precious and extraordinary mosaic (Figure 2). This wall is likely only a small portion of a $300 \mathrm{~m}^{2}$ Roman domus, which is expected to be fully excavated in future archaeological surveys. Hence, the Archaeological Superintendency of Rome needed to assess the integrity of the wall in order to avoid the possible damage or collapse of the wall during the excavations.

Although other geophysical techniques, such as electrical resistivity tomography (ERT), have also been shown to be successful in evaluating the conditions of standing ancient masonry walls and structures (Mol and Preston, 2010; Sass and Viles, 2010; Tsourlos and Tsokas, 2011), we rejected this method here to avoid any damage to the mosaicum and exposed surfaces due to the direct use of conductive gel, which is necessary for coupling the electrodes with the structure.

In the case study presented here, the objectives of the geophysical integrated survey were to identify the presence of anomalous variations within the wall and

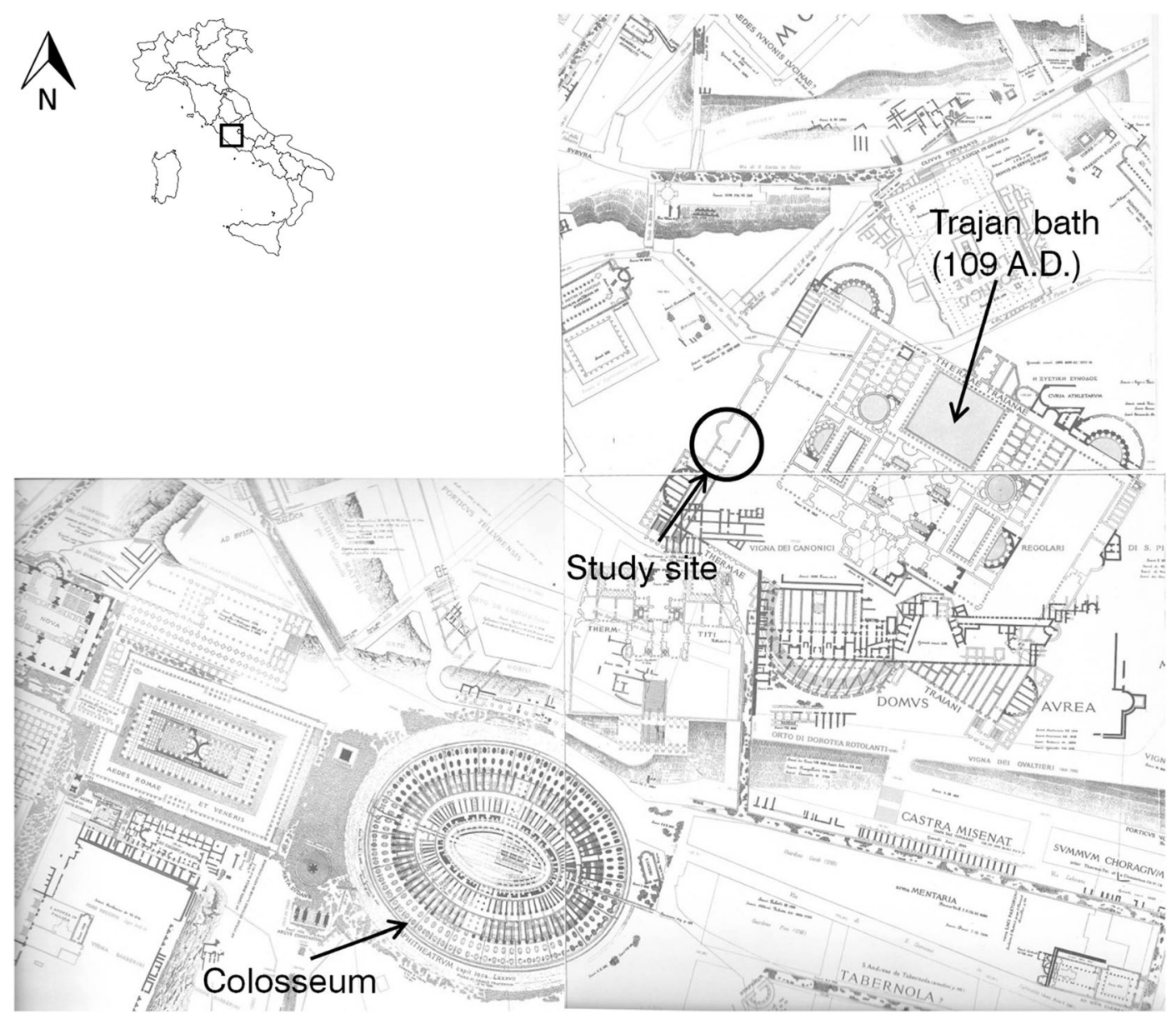

Figure 1. Archaeological map of the study area (Forma Urbis Romae, Lanciani 1893-1901). 
(a)

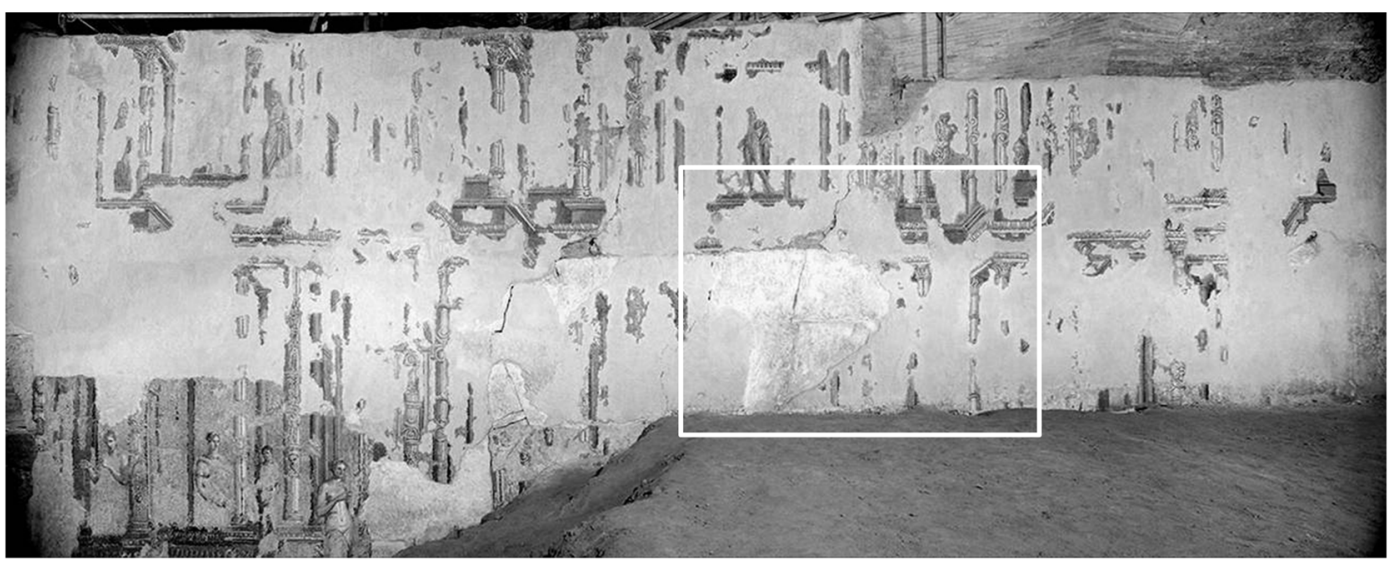

(b)

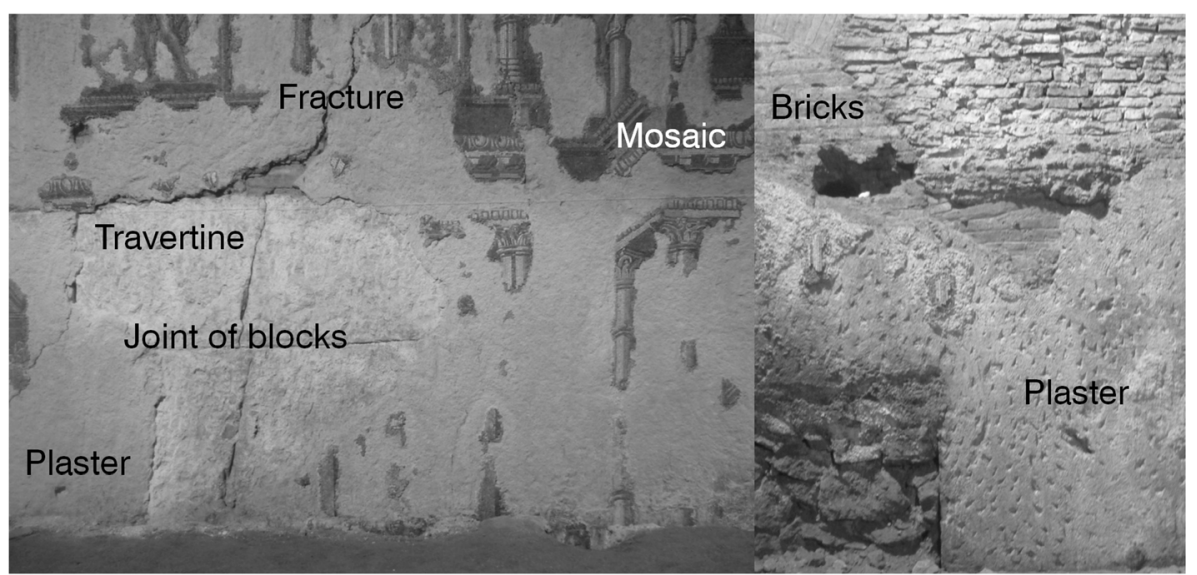

Figure 2. (a) Surveyed wall. (b) Left: enlarged view of the area within the rectangle in (a). Right: detail of the upper part of the wall made of bricks.

understand the composition of its inner structure. Also of importance was to characterize the building material at low strain through seismic tomography. Our ultimate goal was to obtain an accurate map of fractures and weak zones within the wall.

\section{Site description}

The investigated wall is located under the Cryptoporticus of the 'Baths of Trajan' at the Colle Oppio park (Rome historical centre), near the Colosseum (Figure 1). It was part of a luxury building located in the heart of the imperial city of Rome and was contemporary with the famous Domus Aurea ('Golden House') villa built by the Emperor Nero after the great fire in the year AD 64. The building fell into disuse and was partially destroyed by Trajan (AD 53-117) to allow the construction of the Baths, a massive bathing and leisure complex (Figure 1). The wall, discovered by the
Archaeological Superintendency of Rome in 2009, is $15 \mathrm{~m}$ long and $0.9 \mathrm{~m}$ wide. The geophysical survey was performed once the wall had been excavated to a height ranging from 3 to $5 \mathrm{~m}$ (Figure $3 \mathrm{~b}$ ), with an additional $4-5 \mathrm{~m}$ assumed to still be buried.

A preliminary visual survey of the areas where the plaster was removed suggested that the wall is constructed of travertine blocks (in the lower part) and bricks (in the upper part) (Figure 2). In particular, the discontinuity between the travertine blocks and the bricks is exposed in the central part of the wall. The wall was plastered over and partially decorated with a mosaic that likely represents the God Apollo and the Muses (Figure 2).

The wall contains several cracks, which are primarily located in the central part (Figure 2). In light of this surface evidence, mapping the materials constituting the wall (travertine and bricks), defining the elastic parameters of the material, and mapping the cracks and joint of blocks (which are largely covered by plaster 
(a)

(b)

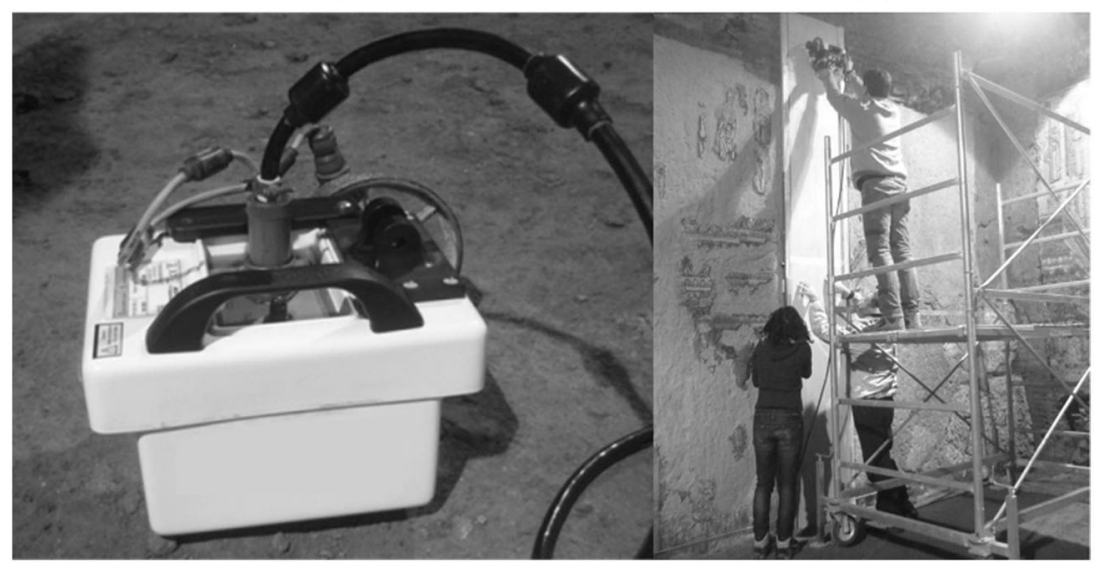

Figure 3. (a) $900 \mathrm{MHz}$ antenna. (b) GPR acquisition on plywood panels.

and mosaics) are crucial for the preservation of the structure and the safety of future excavations.

\section{GPR survey: data acquisition and processing}

For the GPR survey, preliminary data collection was first performed to define the optimal antenna frequency in terms of resolution and penetration depth and also to determine the acquisition methods that would preserve the integrity of the mosaic. We tested three different frequencies $(600 \mathrm{MHz}, 900 \mathrm{MHz}$ and $2 \mathrm{GHz}$ ) with different acquisition layouts and several protective materials (polystyrene, plastic sheet, corrugated cardboard, plywood) between the wall's face and the antennas to avoid damaging the mosaic during data acquisition. Our tests showed that the best trade-off between resolution and investigation depth was using the $900 \mathrm{MHz}$ antennas (Figure 3a) with a plywood panel $(80 \mathrm{~cm} \times 300 \mathrm{~cm})$ (Figure $3 \mathrm{~b}$ ) backed with polystyrene. The panel allowed us to preserve the integrity of the mosaics during the GPR survey, although it slightly reduced the radar wave penetration.

The surface of the wall was divided into rectangular geo-referenced sub-areas and surveyed to collect vertical and horizontal reflection profiles spaced $20 \mathrm{~cm}$ apart (Figure 4). Collection parameters are shown in Table 1.

Reflection profiles were processed in a number of ways in order to define the best processing sequence. An example of a vertical reflection profile (the location of which is indicated in Figure 4) after the application of zero time correction, vertical band pass filter (200-1200 MHz), horizontal mean filter (averaging three traces), and linear gain is shown in Figure 5. This profile (A- $\mathrm{A}^{\prime}$ in Figure 4) investigated both the travertine blocks (in the lower part of the wall) and

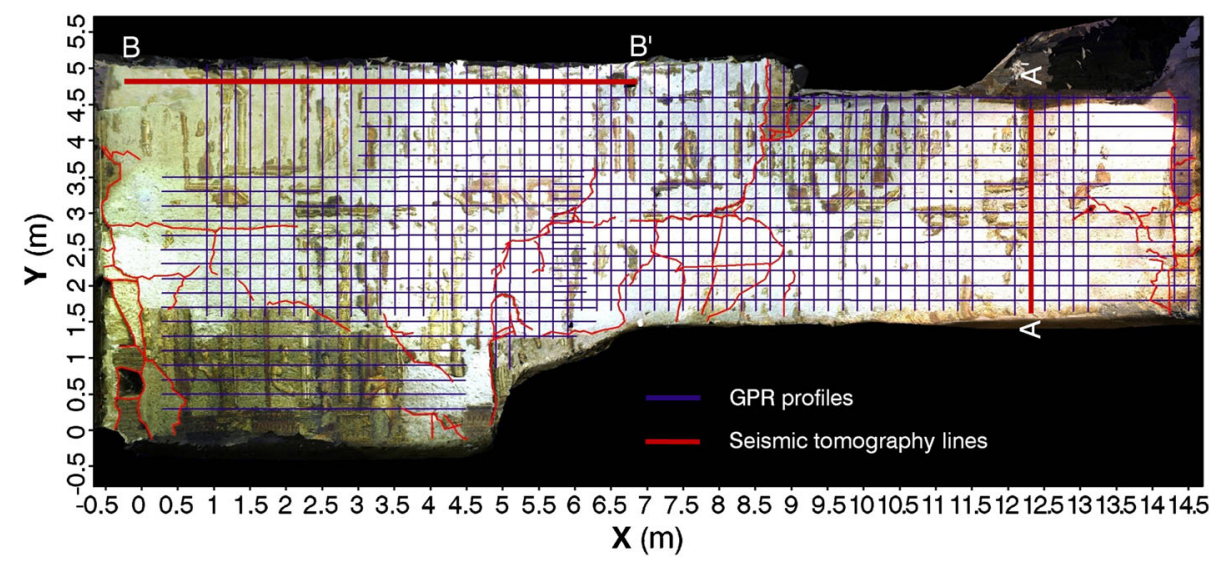

Figure 4. Location of GPR profiles and seismic tomography lines. This figure is available in colour online at wileyonlinelibrary.com/journal/arp 
Table 1. Parameters for GPR data acquisition.

Profile spacing: $20 \mathrm{~cm}$ ( $X$ and $Y$ directions)

Covering material: plywood and polystyrene

Device: IDS $900 \mathrm{MHz}$ antenna

Trace increment: $0.008 \mathrm{~m}$

Samples per scan: 512

Time window: $60 \mathrm{~ns}$

the bricks (in the upper part). The GPR data reveal the different reflected wave signatures of the two materials in terms of signal attenuation and amount of reflected and diffracted energy (backscatter).

Bricks are characterized by higher heterogeneity and energy attenuation than the travertine. As the penetration depth is different between the materials, the GPR data investigated the full thickness of the wall $(90 \mathrm{~cm})$ in the travertine and only the part closest to the wall surface (approximately $40 \mathrm{~cm}$, based on a velocity of $9 \mathrm{~cm} / \mathrm{ns}$ ) in the brick portion (Figure 5a). The different signal response of the two materials is evident in Figure $6 a$, where the absolute values of true amplitude traces (averaged over the travertine and bricks portion of the $\mathrm{A}-\mathrm{A}^{\prime}$ profile in Figure $5 \mathrm{a}$, respectively) are displayed. Additionally, Figure 6a shows that the rear face of the wall is clearly detected in the travertine portion and not in the brick portion. However, where the respective amplitude spectra are displayed (Figure 6b), the two materials are characterized by a similar frequency range (approximately 100-1200 MHz). The low-frequency peak is related to the low frequency background noise (Annan, 2009) and the highfrequency peak to the antenna frequency.

With this preliminary analysis, we applied two different processing flows (indicated as $\mathrm{A}$ and $\mathrm{B}$ in Figure 7). Both the processing flows encompass static correction and the application of a vertical filter. In the processing flow named A, we further apply a background removal and a migration procedure without using any gain. The A processing flow, preserving the true amplitudes, is intended to highlight the presence of bricks or travertine.

In contrast, the B processing flow is more standard and includes also the application of an exponential gain after a horizontal filter, for imaging the internal structure of the wall.

In the interpretation, we take into account both the horizontal and vertical profiles and the three-dimensional data cube built with the horizontal profiles was used to extract timeslices at different times.

In detail, the vertically collected reflection profiles, obtained through the B processing flow procedure, allowed us to detect the position of cracks and joints between different blocks. The detection of lateral discontinuities due to joints between bricks and

(a)

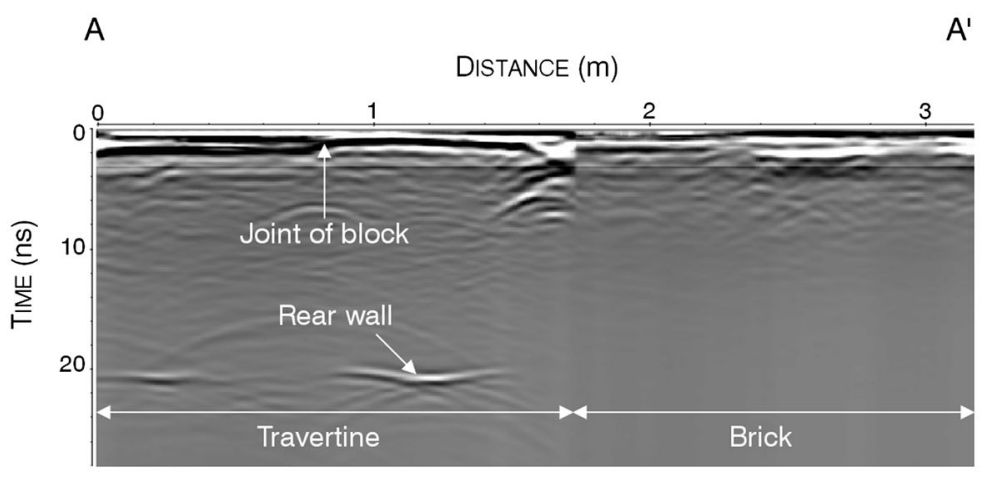

(b)

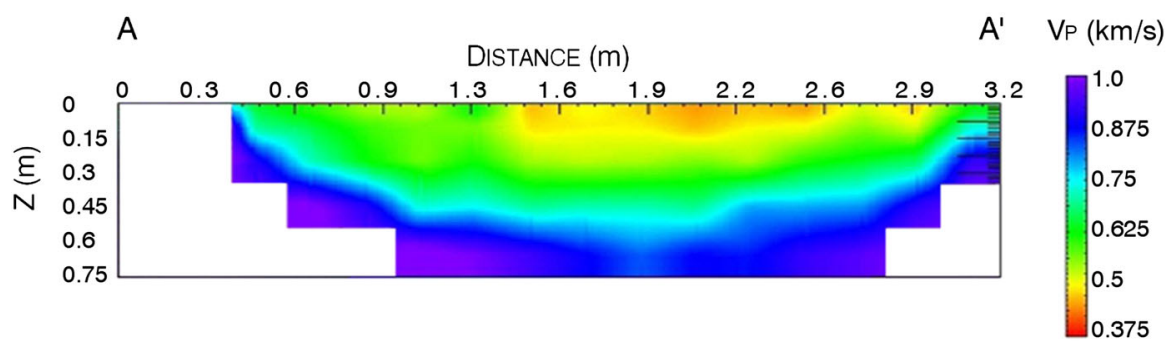

Figure 5. (a) GPR A-A' profile. (b) P-wave velocity model resulting from the inversion of seismic refraction tomography data acquired on the A-A' profile (see Figure 4 for the location of profile). This figure is available in colour online at wileyonlinelibrary.com/journal/arp 


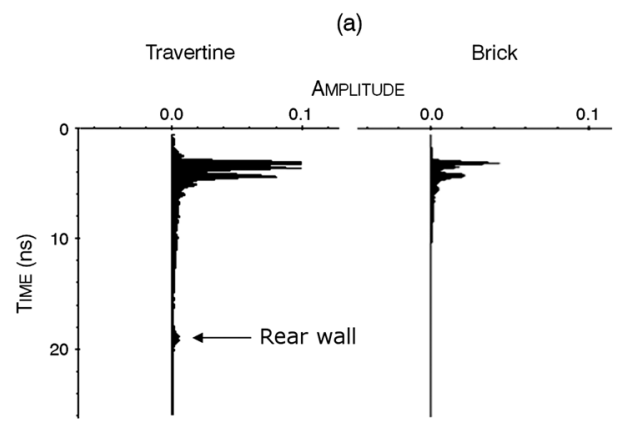

(b)

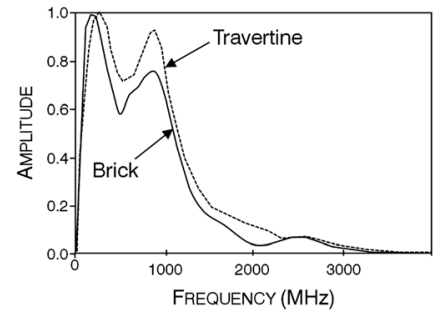

Figure 6. (a) Amplitude of GPR traces acquired on travertine (left) and bricks (right). (b) Normalized amplitude spectra of traces in Figure 7a.

travertine, cracks and joints between travertine blocks was performed manually on each reflection profile and then correlated between contiguous profiles. The correlation was based on the signature characterizing each discontinuity. Although this approach is highly biased by the interpreter, this method represents the best procedure for processing data acquired on a $20 \mathrm{~cm} \times 20 \mathrm{~cm}$ grid, where the maximum displacement of the discontinuities is approximately $2-3 \mathrm{~cm}$. The map of discontinuities (Figure 8) shows that most are located in the central portion of the wall and in the travertine blocks. This is consistent with the visual detection of the fractures visible on the wall (Figure 2b) and with the typology of material. In fact, the strain in the travertine induces persistent fractures, whereas the bricks are likely to develop fractures between the bricks in the mortar. The horizontal discontinuities indicated with black arrows in Figure 8 are related to the layered structure of the wall.

Subsequently, we retrieved additional information on the materials forming the wall by mapping the processed data as timeslices in vertical slices of the wall at different times away from the wall face. Time-depth conversion of slices used a velocity of $9 \mathrm{~cm} / \mathrm{ns}$, determined by diffraction hyperbola fitting (Conyers, 2013).

The intensity of the backscatter energy differs significantly between the travertine and bricks; therefore, mapping the timeslice computed using the A processing flow and calculated for the entire wall $(90 \mathrm{~cm})$, allows us to detect the portions of the wall composed of bricks or travertine (Figure 9). High-intensity backscatter energy (red areas in Figure 9) is related to the travertine, whereas low-intensity backscatter energy (green-yellow areas) is related to the bricks. These relationships were validated by the correlation of the intensity of the backscatter energy with the direct inspection of the wall in areas without plaster. Figure 9 reveals a high-energy zone located in the lower part of the wall (travertine blocks) and a low-energy zone in the upper part. Because the intensity of backscatter energy varies significantly passing from the left part of the slice $(X=0-4 \mathrm{~m})$ to the right part $(X=4-12 \mathrm{~m})$, the travertine blocks themselves exhibit heterogeneous properties, which are likely related to composition,

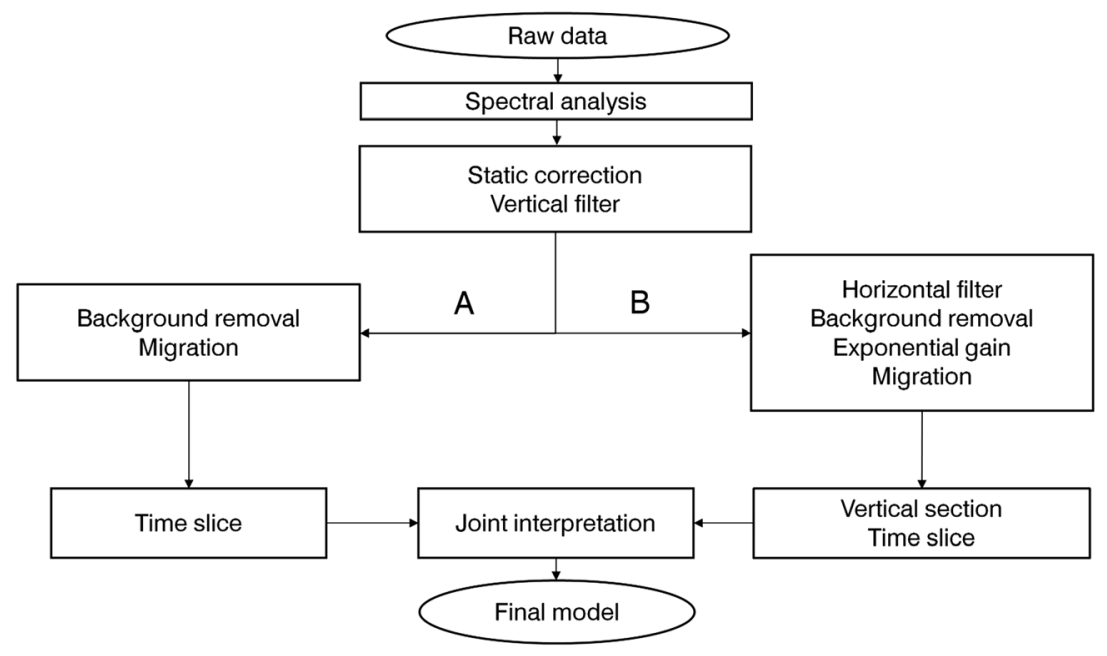

Figure 7. Flow chart of GPR data processing. 


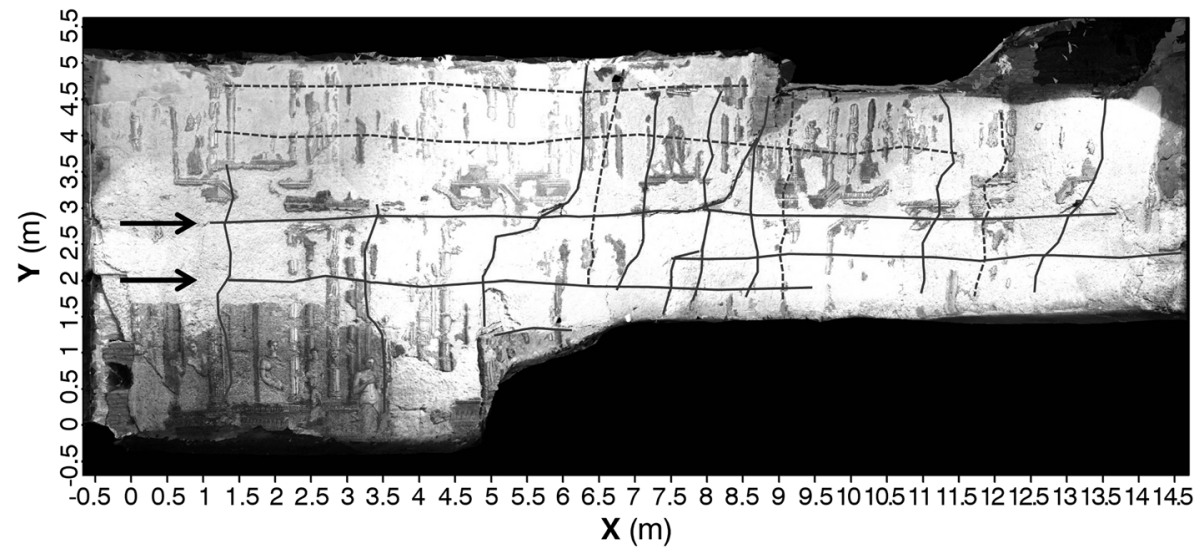

Figure 8. Location of discontinuities detected by GPR (cracks, joints and blocks of travertine). The upper arrow indicates the interface between travertine and bricks, whereas the lower arrow points out the discontinuity between two different layers of travertine blocks.

quality and integrity. The low intensity of backscatter energy in the lower left part of the timeslice indicates the presence of bricks instead of travertine, information which is not available solely from visual observation. Due to the shape of this anomaly, the archaeologists estimate that it is due to a door walled up with bricks.

The timeslices calculated following the B-mode processing shown in Figure 7 were used to locate the major anomalies inside the wall. The most meaningful anomalies were detected by the timeslices associated with the depths from 0 to $20 \mathrm{~cm}$ (Figure 10) and from 30 to $50 \mathrm{~cm}$ (Figure 11) from the antenna position. For 0 to $20 \mathrm{~cm}$ (Figure 10), we detected several well-aligned anomalies (indicated with black ellipses). They are located along the $X$-direction in the transition zone between two rows of travertine blocks; these anomalies are probably due to the coupling elements between the blocks. The upper part of the wall exhibits several misaligned anomalies, probably due to the edges of bricks.
For 30 to $50 \mathrm{~cm}$ (Figure 11), the timeslice shows several obvious anomalies in both the travertine and the bricks. The wider and better defined of these anomalies are indicated with circles and are located in the bricks. The rectangle on the left side of the wall marks a high-intensity scattering area $(Y=2$ and $3 \mathrm{~m})$, which is likely related to low-quality travertine blocks.

\section{P-wave seismic tomography}

P-wave seismic tomography was performed to obtain the elastic (low-strain) characterization of the wall and its elements. Two separate seismic tomography experiments were performed consisting of two profiles (Figures 4 and 12. One was a vertical seismic refraction tomography profile $\left(\mathrm{A}-\mathrm{A}^{\prime}\right)$ on the right side of the wall and a seismic transmission tomography in the upper-left part of the wall $\left(B-B^{\prime}\right)$. The $A-A^{\prime}$ profile (Figure 12a) is $3 \mathrm{~m}$ long and consists of 23 sensors spaced $13 \mathrm{~cm}$ apart. The sensors are

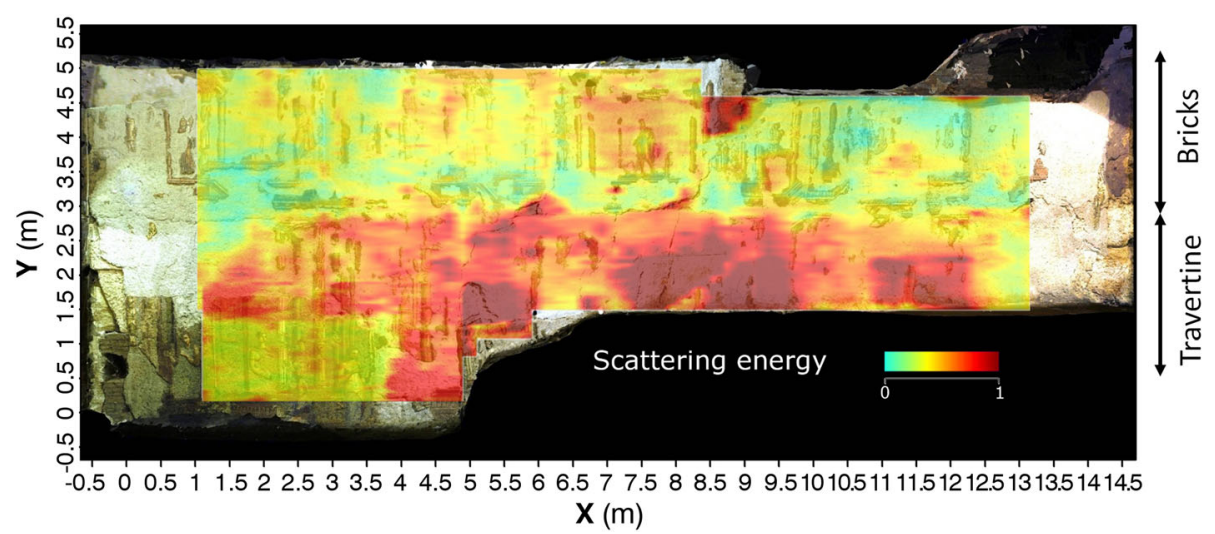

Figure 9. Timeslice calculated using the ungained GPR profiles for a significant thickness of 0 to $90 \mathrm{~cm}$ (equal to the thickness of the wall). This figure is available in colour online at wileyonlinelibrary.com/journal/arp 


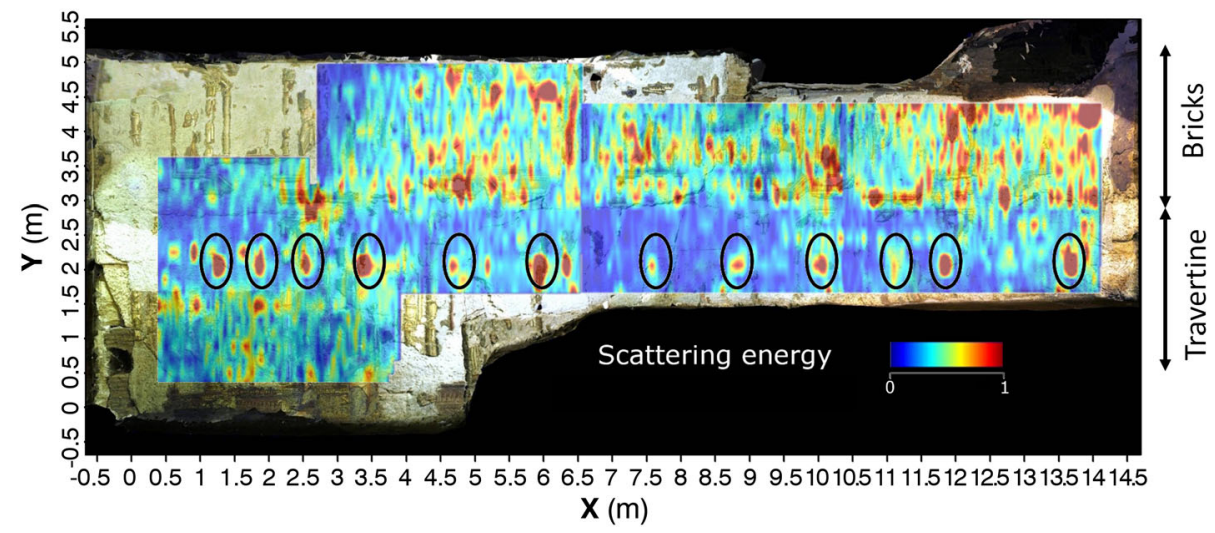

Figure 10. Timeslice calculated using the gained GPR profiles for a significant thickness of 0 to $20 \mathrm{~cm}$. The main anomalies detected are indicated by black ellipses. This figure is available in colour online at wileyonlinelibrary.com/journal/arp

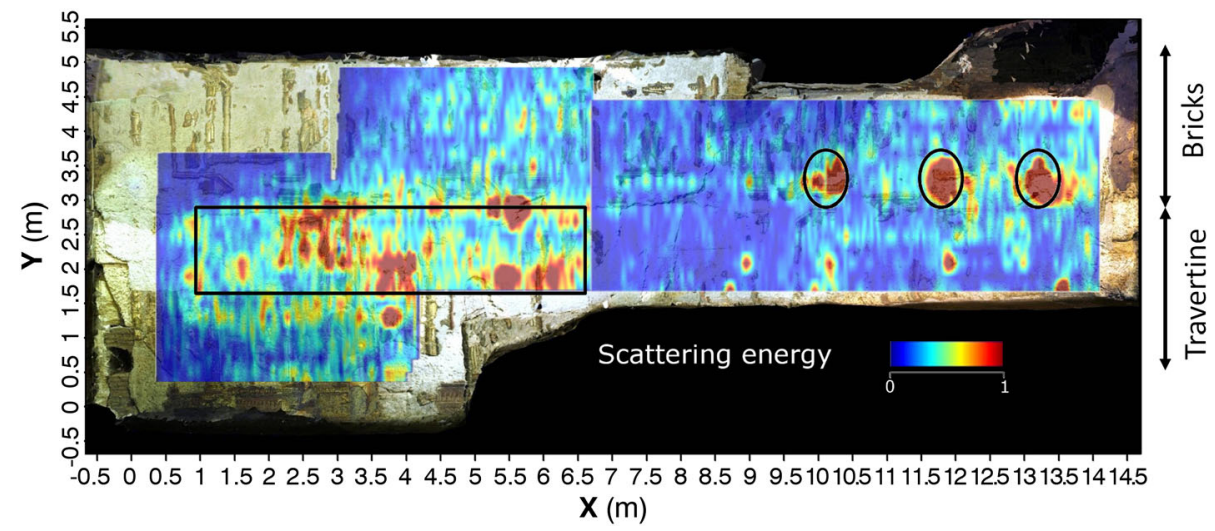

Figure 11. Timeslice calculated using the gained GPR profiles for a significant thickness of 30 to $50 \mathrm{~cm}$. The main anomalies detected are indicated by black ellipses and a black rectangle (high-scatter area). This figure is available in colour online at wileyonlinelibrary.com/journal/arp

piezoelectric accelerometers with a cut-off frequency of $4 \mathrm{kHz}$. To avoid damaging the wall and to enhance the signal-to-noise ratio, the coupling between the wall and the sensors was improved by using sticking plasters and silicone (Figure 12b). The profile was collected using 13 shot points (produced by a $2 \mathrm{~kg}$ hammer source).

To ensure accurate travel time determination for such small times, we used a differential triggering system. A piezoelectric sensor in the hammer is connected to the first channel of the seismograph, and the trigger of the seismograph is activated by the hammer, which interrupts a circuit during its stroke towards the shot point. Therefore, the shot instant is recorded and the travel times are read as the difference between the shot instant and the first breaks of the compressional wave. The sampling rate employed in these surveys is $31.5 \mu$ s. In the case of weak signal-to-noise ratios, we did not stack the recorded seismograms to enhance the quality of first arrivals due to the low repeatability of the source signature. Alternatively, we compared the readings from the single shots repeated for each location, later averaging these readings and manually rejecting outliers. For the $\mathrm{B}^{-} \mathrm{B}^{\prime}$ profile, we used the same equipment described earlier, with the 23 sensors spaced $15 \mathrm{~cm}$ apart. The 19 shot points are located on the decorated side of the wall and the receivers on the back side (Figure 12a).

The parameters used for the seismic data acquisition are reported in Table 2.

For each shot gather and for both the $\mathrm{A}-\mathrm{A}^{\prime}$ and $\mathrm{B}-\mathrm{B}^{\prime}$ profiles, the first arrivals were manually picked and the travel times computed as the difference between the shot instant and the first breaks of the P-wave. These data are inverted using the linear travel time interpolation (LTI) method for ray-tracing in the forward kernel (Asakawa and Kawanaka, 1993; Cardarelli and Cerreto, 2002) and the iterative biconjugate gradient algorithm for travel time inversion (Cardarelli and de Nardis, 2001) as shown in Figure 13a. A typical shot record is displayed in Figure 13b, which shows the shot instant on the first channel generated by the 
(a)

A-A' B-B'

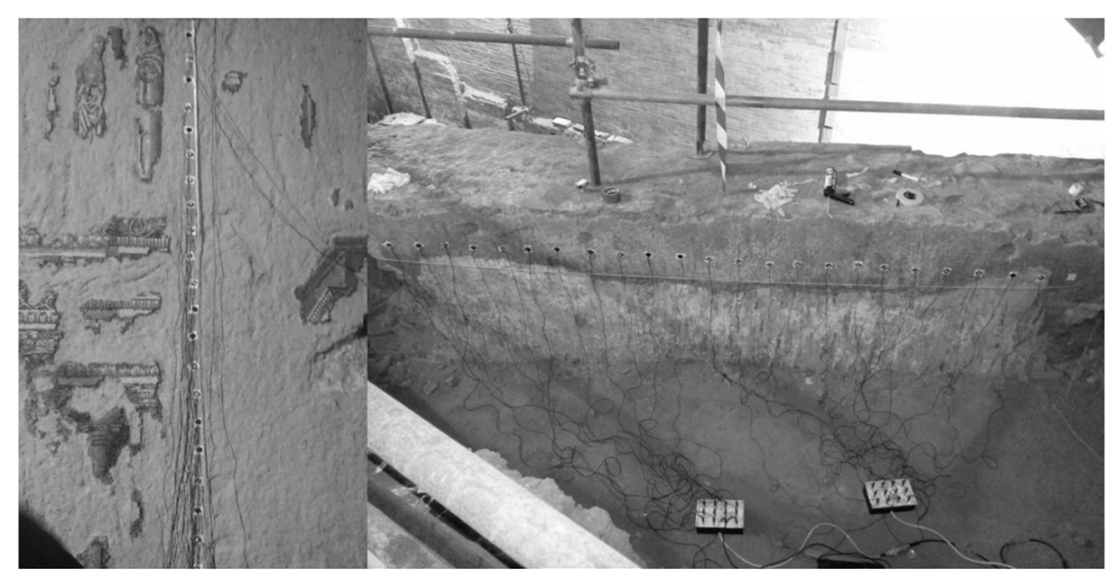

(b)

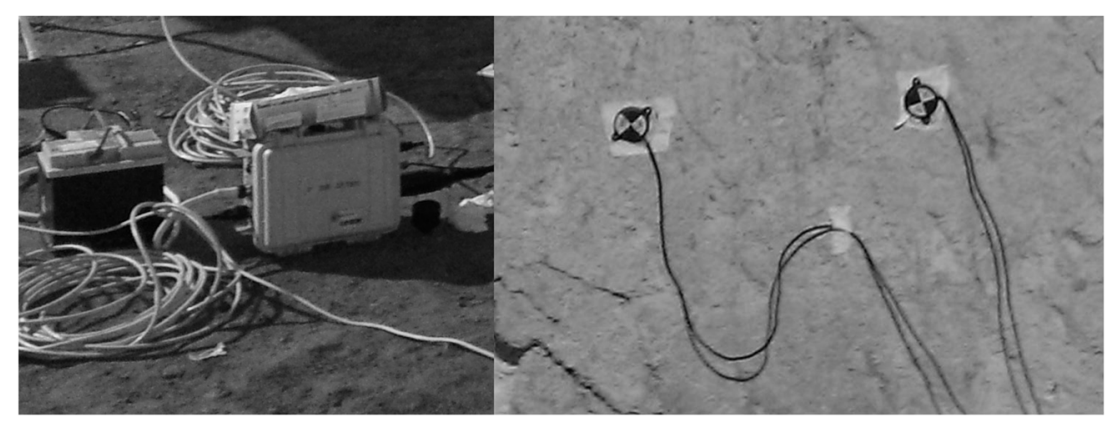

Figure 12. (a) A-A' (left) and B-B' (right) seismic tomography lines. (b) Two 24-channel Geode Geometrics $\odot$ seismographs (left) and piezoelectric sensors (right) were used as receivers.

Table 2. Parameters for seismic data acquisition.

Receivers: 23 piezo-electric sensors $13 \mathrm{~cm}\left(A-A^{\prime}\right)$ and $15 \mathrm{~cm}\left(B_{-}-B^{\prime}\right)$ spaced, with a cut-off frequency of $4 \mathrm{kHz}$

Shots: 13 (A-A') and 19 (B-B') shot points

Source: $2 \mathrm{~kg}$ steel hammer

Device: 1 seismograph Geode Geometrics ${ }^{\odot}$ with 24 channels

Sample rate: $31.5 \mu \mathrm{s}$

piezoelectric sensor located inside the hammer and the picking of the first breaks. The ray-tracing algorithm is capable of calculating the direct and refracted waves at the critical angle. The ray path is influenced by the grid choice as the seismic rays may be refracted only at the cell boundaries (Figure 13c). Because the dimension of the cell determines the size of the minimum detected anomaly, we used the Fresnel ray theory to determine the proper cell size. With $r_{\text {min }}$ representing the minimum dimension of the cells, the proper cell size can be calculated with the following expression (Červený and Soares, 1992):

$$
r_{\min }=\frac{1}{2} \sqrt{\frac{L v}{f}}
$$

where $L$ is the distance between the source and the receiver, $v$ is the mean velocity of the medium and $f$ is the dominant frequency of the signal.

The investigated wall exhibits a high degree of heterogeneity not only along the $X$ and $Y$ axes but also in the $Z$ direction, which indicates the distance from the wall face. The parts of the wall that are closer to the decorated surface exhibit lower P-wave velocities compared to the material inside the wall. In the inverted section of the seismic refraction tomography $\mathrm{A}-\mathrm{A}^{\prime}$ (Figure $5 \mathrm{~b}$ ), the $\mathrm{P}$-wave velocity clearly decreases (from approximately $700 \mathrm{~m} / \mathrm{s}$ to $500 \mathrm{~m} / \mathrm{s}$ ) at the wall surface when passing from the travertine blocks to the bricks $(X=1.4-1.5 \mathrm{~m}$ in Figure $5 \mathrm{~b})$. However, for both the travertine and the bricks, the seismic velocity tends to increase away from the wall face, which is consistent with the coincident GPR profile (Figure 5a). 
(a)

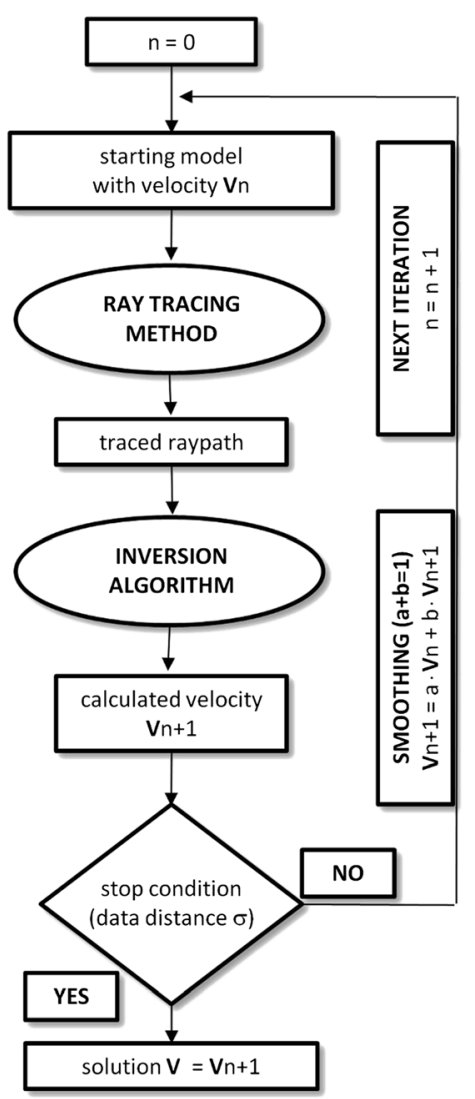

(b)

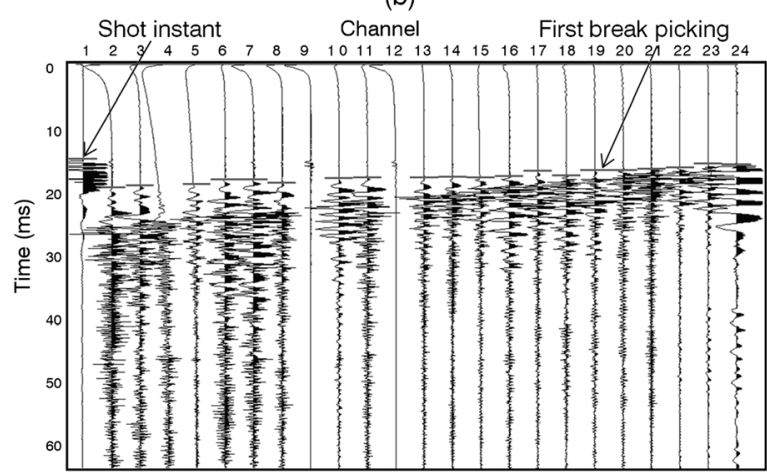

(c)

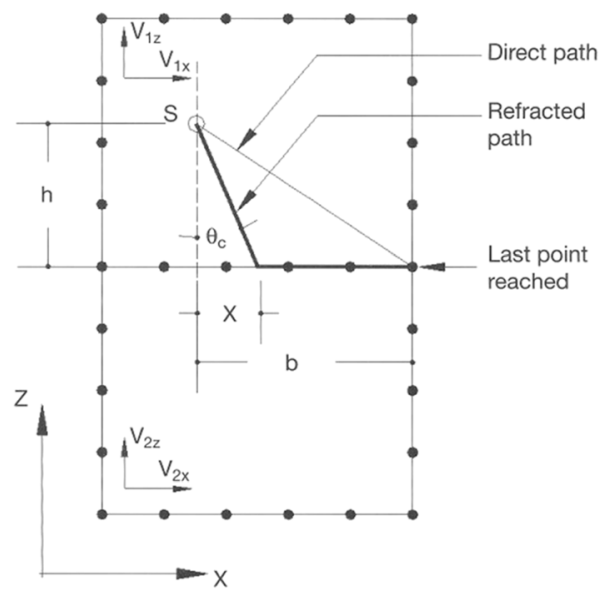

Figure 13. (a) Flow chart of seismic tomography data processing. (b) Example of a recorded shot gather on the A-A' line with picked P-wave arrivals. (c) Refraction at the critical angle.

(a)

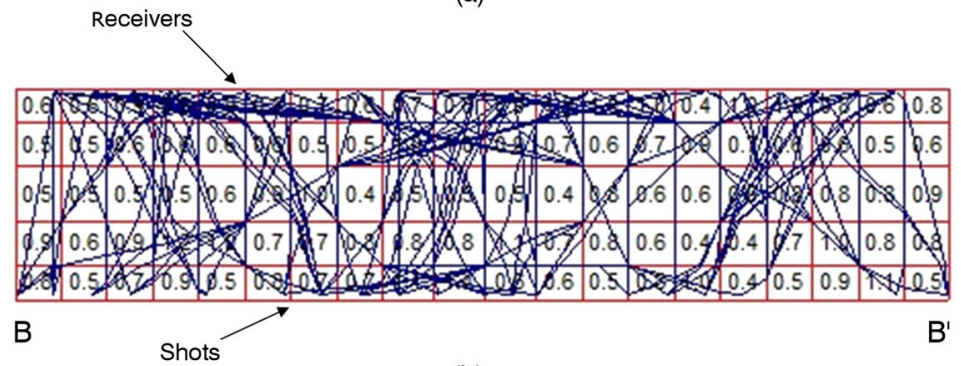

(b)

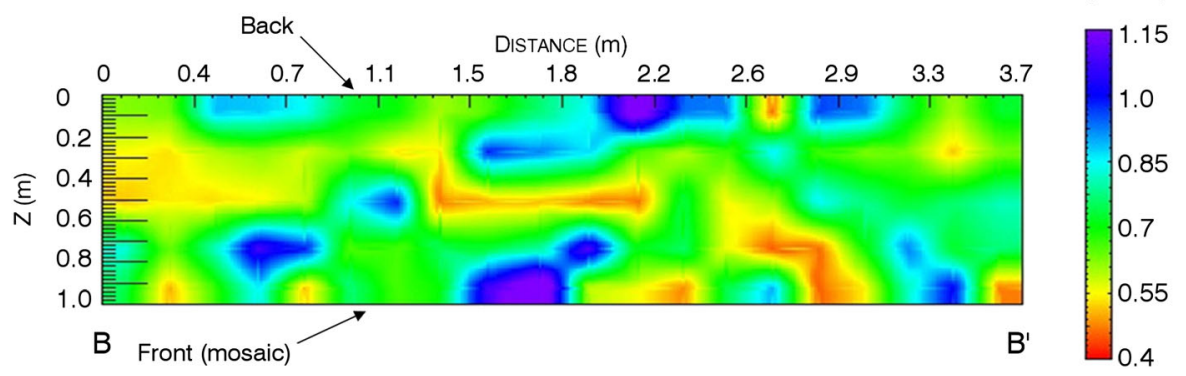

Figure 14. Inversion of the seismic transmission tomography data acquired on the B-B' profile (see Figure 4 for the location of profile). (a) Ray tracing and final $\mathrm{P}$-wave velocities for each cell and (b) P-wave velocity model resulting from contouring of the values in (a). This figure is available in colour online at wileyonlinelibrary.com/journal/arp 
The cells with poor ray coverage (white pixels) have been excluded from the tomographic reconstruction.

The inverted model of the seismic transmission tomography $\mathrm{B}-\mathrm{B}^{\prime}$ (Figure 14) provides a more heterogeneous picture of the internal section of the wall. As this seismic line is located entirely on bricks, the differences in the velocity distribution (and consequently in the composition) can be attributed to the peculiar construction using the opus caementicium technique, with bricks in the outer part of the structure. These were constructed as a mixture of aggregate, water and Pozzolanic ash (a Quaternary volcanic deposit), which has poor mechanical characteristics, in the inner part. The values of the P-wave velocity detected in this case correspond to the mean values of a brick wall in good condition (Cardarelli and de Nardis, 1998). The considerable variations in the velocity values depend on the high degree of heterogeneity in the mixture forming the inner part of the wall, consisting of the hydrated Pozzolana-based mortar that generally includes pieces of rock and crushed brick rubble (generally from previously demolished buildings).

\section{Discussion and conclusions}

The non-invasive geophysical mapping of physical properties is key to successfully preserving cultural heritage sites. Knowledge of the physical properties of the building materials is essential in any restoration intervention, as described here, to provide new information on archaeological remains. The choice of the investigation methods used to achieve a characterization of the inner structure by using relevant physical properties depends on several factors, such as the size and geometry of the structure, the desired resolution and the composition of the building materials.

GPR provided the means to accurately characterize (with high resolution) the joints and cracks not exposed to visual identification. Seismic tomography, although lower resolution than GPR, provided data for the entire thickness of the wall in the travertine as well as in the brick and mortar parts of the wall, providing direct information on its elastic properties.

The use of integrated geophysical methods, such as GPR and seismic tomography, allowed us to characterize a pre-Trajan Roman structure, to assess the conservation status of the construction materials and to locate and quantitatively describe the geometry and typology of major fractures and discontinuities.

As a summary of our findings, we present in Figure 15 the reconstructed model of the wall, in which the discontinuities and the geophysical anomalies are highlighted. More specifically, the discontinuities were detected by the combined analysis of the vertical and horizontal GPR profiles and the amplitude slices encompassing both the travertine and the bricks. Where the timeslices are mapped without applying gain, the differences in terms of quality and composition of the construction materials are more evident because the attenuation is directly correlated to lithology.

Additionally, the two seismic profiles confirm the evidence obtained from GPR analysis by providing estimates of the variable stiffness of the two construction materials (travertine or bricks, cross-section $\mathrm{A}-\mathrm{A}^{\prime}$ in Figure 4) or among the same material (cross-section B-B' in Figure 4). In areas with a high degree of heterogeneity, the low-velocity zones correspond to poor mechanical properties.

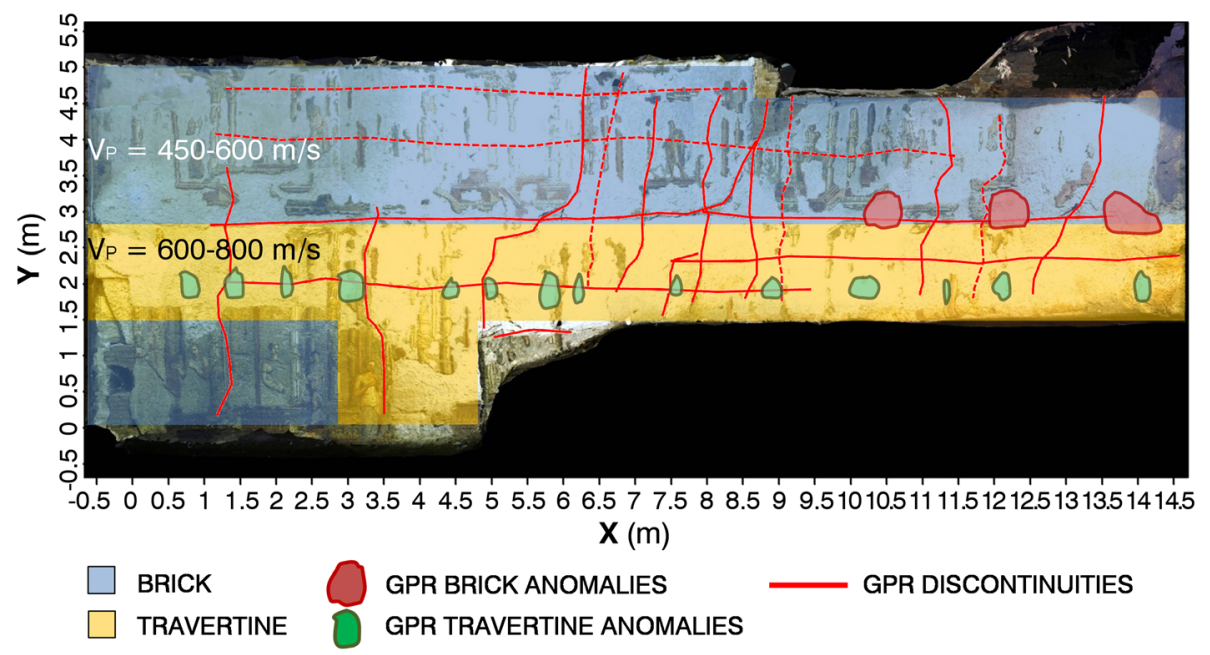

Figure 15. Reconstructed model of the wall. This figure is available in colour online at wileyonlinelibrary.com/journal/arp 
The resulting high-resolution map of the wall reported in Figure 15 confirms the consistency of the joint interpretation of different non-invasive techniques. These findings can help the archaeologists to accurately plan future excavations while prioritizing the integrity of the wall and, consequently, the precious surface mosaic. The joint interpretation procedure described earlier can be applied to vertical or horizontal structures (walls, concrete elements, foundations) with the aims of evaluating their integrity and general conditions and providing guidance for restoration activities.

\section{Acknowledgements}

This research was partially supported by an 'Ateneo 2012' grant from 'Sapienza' University of Rome entitled 'Non-destructive tests in the diagnosis of pavements and structures' (prot.C26A12PFNS) (Scientific coordinator: Luciana Orlando).

The authors thank Rita Volpe for allowing them to survey the structure and for the archaeological support, and Beatrice Renzi, Francesca Verri, Silvia Salviani and Francesco Pugliese for their help during data acquisition. We thank the anonymous reviewers and Editor L.B. Conyers for their accurate reviews and constructive remarks that greatly improved the paper.

\section{References}

Annan AP. 2009. Electromagnetic principles of ground penetrating radar. Joil HM (Ed.) Ground Penetrating radar: Theory and applications. Elsevier: Amsterdam.

Asakawa E, Kawanaka T. 1993. Seismic ray tracing using linear travel time interpolation. Geophysical Prospecting 41(1): 99-111. DOI:10.1111/j.1365-2478.1993.tb00567.x.

Cardarelli E, Cerreto A. 2002. Ray tracing in elliptical anisotropic media using linear travel-time seismic interpolation (LTI) method applied to travel time seismic tomography. Geophysical Prospecting 50(1): 55-72. DOI:10.1046/j.1365-2478.2002.00297.x.

Cardarelli E, de Nardis R. 1998. The use of 3D and 2D seismic tomography for assessing the physical integrity of building panels. European Journal of Environmental and Engineering Geophysics 3: 131-142.

Cardarelli E, de Nardis R. 2001. Seismic refraction, isotropic anisotropic seismic tomography on an ancient monument (Antonino and Faustina temple a.d. 141). Geophysical Prospecting 49(2): 228-240. DOI:10.1046/ j.1365-2478.2001.00251.x.

Cardarelli E, Godio A, Morelli G, Sambuelli L, Santarato G, Socco LV. 2002. Integrated geophysical surveys to investigate the Scarsella vault of St. John's Baptistery in Florence. The Leading Edge 21(5): 467-470. DOI:10.1190/ 1.1481255.

Cataldo R, D'Agostino D, Leucci G. 2012. Insight into the buried archaeological remains at the Duomo of
Lecce (Italy) using ground penetrating radar surveys. Archaeological Prospection 19(3): 157-165. DOI:10.1002/ arp.1423.

Červený V, Soares EP. 1992. Fresnel volume ray tracing. Geophysics 57(7): 902-915. DOI:10.1190/1.1443303.

Conyers LB. 2013. Ground-penetrating Radar for Archaeology, 3rd edn. Laytham, MD: Rowman and Littlefield Press.

Daniels DJ. 2009. Ground Penetrating Radar, 2nd edn. IET: London; 734.

Goodman D, Piro S. 2013. GPR Remote Sensing in Archaeology. Springer: Berlin; 233.

Mavko G, Mukerji T, Dvorkin J. 2009. The Rock Physics Handbook: Tools for Seismic Analysis of Porous Media. Cambridge University Press: Cambridge; 329.

Mol L, Preston PR. 2010. The writing's in the wall: a review of new preliminary applications of electrical resistivity tomography within archaeology. Archaeometry 52(6): 1079-1095. DOI:10.1111/j.1475-4754.2010.00516.x.

Neubauer W, Eder-Hinterleitner A, Seren S, Melichar P. 2002. Georadar in the Roman civil town Carnuntum, Austria: an approach for archaeological interpretation of GPR data. Archaeological Prospection 9(3): 135-156. DOI:10.1002/arp.183.

Orlando L, Renzi B. 2013. Non-destructive testing to the characterization of Moai statues (Easter Island-Chile). Archaeological Prospection 20(1): 23-37. DOI:10.1002/ arp.1436.

Orlando L, Slob E. 2009. Using multicomponent GPR to monitor cracks in a historical building. Journal of Applied Geophysics 67(4): 327-334. DOI:10.1016/j. jappgeo.2008.09.003.

Oswin J. 2009. A Field Guide to Geophysics in Archaeology. Springer: Berlin; 221.

Pérez-Gracia V, Caselles JO, Clapés J, Martinez G, Osorio R. 2013. Non-destructive analysis in cultural heritage buildings: evaluating the Mallorca cathedral supporting structures. NDT \& E International 59: 40-47. DOI:10.1016/j. ndteint.2013.04.014.

Piro S. 2009. Introduction to geophysics for archaeology. In Seeing the Unseen: Geophysics and Landscape Archaeology, Campana S, Piro S (eds). CRC Press: London; 27-64.

Piro S, Goodman D, Nishimura Y. 2003. The study and characterization of Emperor Traiano's villa (Altopiani di Arcinazzo, Roma) using high-resolution integrated geophysical surveys. Archaeological Prospection 10(1): 1-25. DOI:10.1002/arp.203.

Polymenakos L, Papamarinopoulos S, Miltiadou A, Charkiolakis N. 2005. Investigation of the foundations of a Byzantine church by three-dimensional seismic tomography. Journal of Applied Geophysics 57(2): 81-93. DOI:10.1016/j.jappgeo.2004.08.004.

Sass O, Viles HA. 2010. Wetting and drying of masonry walls: 2D-resistivity monitoring of driving rain experiments on historic stonework in Oxford, UK. Journal of Applied Geophysics 70(1): 72-83. DOI:10.1016/j. jappgeo.2009.11.006.

Tsourlos PI, Tsokas GN. 2011. Non-destructive electrical resistivity tomography survey at the south walls of the Acropolis of Athens. Archaeological Prospection 18(3): 173-186. DOI:10.1002/arp.416. 